\title{
Comunidades Humanistas ante el Transhumanismo
}

\section{doi: 10.52749/fh.v2i2.7}

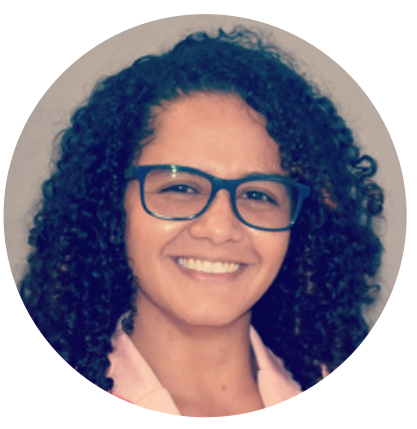

\section{MARCELA GÓMEZ}

Coordinadora STEM del Colegio Colombo Hebreo (Colombia). Fundadora del Colectivo Tejido STEM Colombia. Miembro del Colectivo Nacional de Educación STEM - CONASTEM y del Colectivo Latinoamericano Manifiesto STEAM. Miembro asesor de la Mesa Técnica Nacional de Educación STEM+A para el Ministerio de Educación Nacional de Colombia. Ingeniera mecánica y Magíster en ciencias naturales y matemática de la Universidad Pontificia Bolivariana (Colombia). Diplomada en educación STEM/STEAM por la OEA. STEM.org Certified Educational Instructor.

marcelagq1987@gmail.com

(0) @marcela.stem

Resumen. El artículo inicia con dos preguntas provenientes de un experimento informal cuyo propósito fue observar la reacción cotidiana ante el término transhumanismo. Acto seguido, el término se define de manera breve para dar paso a varias referencias que a lo largo de la historia han sugerido un interés por preservar la vida humana trascendiendo las barreras de la corporeidad. Posteriormente, y siguiendo con el llamado de estas fuentes, se mencionan algunos modelos más detallados en torno a las alternativas para la modificación de la corporeidad humana en aras de su trascendencia, los cuales tienen como punto en común la adaptación a un hábitat modificado. Finalmente, se habla de la humanización como camino para lograr este proceso de adaptación a un hábitat en permanente cambio.

Palabras clave: comunidad, hábitat, humanización, transhumanismo

"[...]La gente teme el cambio porque teme lo desconocido. Pero la única y mayor constante de la historia es que todo cambia." (Harari, 2015, p. 83)

Para comenzar, un comentario trivial: el término transhumanismo aún se encuentra revestido de un temeroso misterio que evoca el oscurantismo del pasado milenio; mencionar el término al ciudadano de a pie puede arrojar como resultado un prolongado titubeo, un empecinado silencio, o una escueta negativa. Es posible afirmar que una respuesta similar se obtiene al indagar respecto del tema con individuos en el sistema escolar básico secundario. ¿Qué respalda este comentario? Un experimento rápido realizado con personas de diversas edades, roles y hábitos, cuyo único punto en común fue cruzarse conmigo en algún momento e iniciar una conversación bajo cualquier pretexto.

Entre otras tantas, dos preguntas resultan como consecuencia de este experimento exprés:

1. ¿Por qué este término, cada vez más cercano y plausible, sigue siendo ignorado en la cotidianidad?

2. ¿Cómo puede responder una persona, habitante de este tiempo, de manera acertada ante las circunstancias e implicaciones del trans- transhumanismo?

El intento de responder a estas preguntas requiere acotar sus definiciones fundamentales para asegurar un acercamiento a la perspectiva esperada en el ciudadano estándar. Así, el transhumanismo se define como un sistema de pensamiento que promueve el mejoramiento humano desde la trascendencia de sus limitaciones biológicas con el propósito de catalizar la evolución de la vida inteligente a través de una forma más compleja de la misma (Gayozzo, 2021). Podría explicarse, en otras palabras, como aquel sistema de pensamiento que propende por la evolución de la humanidad desde la disminución (incluso podría pensarse en la anulación) de aquellas restricciones biológicas que le impiden trascender en el tiempo y lograr un impacto directo mucho más prolongado en el mundo y sus circunstancias.

Esta definición trae a la mente una serie de referencias y guiños presentes en diversas obras a lo largo de la historia. Por supuesto, las mismas respondieron a los interrogantes vigentes en sus correspondientes épocas, tales como el origen del hombre y de la Naturaleza, centrándose las primeras en la naturaleza humana justificada desde la existencia del alma. Un ejemplo clásico es la 
postura dual de Platón, que otorga estados claramente diferenciados e incluso estratificados entre el alma y el cuerpo [1], es decir, respuestas de nivel superior en el primer caso y de nivel inferior en el segundo; asegura que es el alma quien provee de animación a los cuerpos, mientras que los cuerpos sin alma dependen de agentes externos para moverse:

"Todo cuerpo, en efecto, que recibe de fuera su movimiento es inanimado, mientras que el que lo tiene dentro y lo recibe de sí mismo es animado, porque es ésta la naturaleza del alma. Y si esto es así, si lo que mueve a sí mismo no es otra cosa que el alma, necesariamente será el alma ingénita e inmortal" (Fedro, 245).

En otro fragmento platónico, se muestra mayor detalle en torno a la naturaleza del alma, la cual hace ver la inmortalidad como algo posible:

"-Considera ahora, Cebes -prosiguió-, si de todo lo dicho no resulta que es a lo divino, inmortal, inteligible, uniforme, indisoluble y que siempre se presenta en identidad consigo mismo y de igual manera, a lo que más se asemeja el alma, y si, por el contrario, es a lo humano, mortal, multiforme, ininteligible, disoluble, y que nunca se presenta en identidad consigo mismo, a lo que, a su vez, se asemeja el cuerpo. (...) ¿No le corresponde al cuerpo el disolverse prontamente y al alma, por el contrario, el ser completamente indisoluble, o el aproximarse a ese estado?" (Fedón, 79, e)

Según lo anterior, la naturaleza no corpórea del hombre debe mantenerse indisoluble, inmortal, pero su cuerpo es el impedimento para que esto ocurra. Esta condición, por tanto, sugiere que la humanidad puede ser inmortalizada siempre y cuando su alma mantenga este carácter indisoluble y se logre la eliminación del obstáculo que constituye la finitud del cuerpo [2]. La pregunta ahora es: ¿cómo eliminar el obstáculo de la finitud corpórea?

Documentos de naturaleza diversa, escritos en tiempos modernos y contemporáneos, presentan modelos más concretos y perspectivas más fácilmente visualizables; mientras las fuentes más conocidas y discutidas en términos filosóficos incluyen los trabajos de Nietzsche (1967; citado por Sorgner, 2009), Habermas (2001; citado por Sorgner, 2009), y posteriormente de Bostrom (2001; 2005; 2006), las fuentes para estos modelos, que pueden considerarse de carácter divulgativo o enmarcarse en el género narrativo, incluyen el Codex Seraphinianus (1985), Homo Deus (Harari, 2015) y Fahrenheit 451 (Bradbury, 2019). El común denomi- nador en este pequeño catálogo de fuentes es la transformación del hábitat que rodea a la especie de interés, en este caso al ser humano, entre otras cosas, a través de la reconfiguración de la concepción que el individuo tiene de sí mismo y de su rol en la comunidad a la cual pertenece (Gómez Quintero, 2019; 2021), lo cual le lleva a desarrollar y democratizar nuevas y mejores maneras de configurar el entorno que le abriga (Oppenheimer, 2014). De hecho, la Cuarta Revolución Industrial en la cual estamos globalmente embebidos, es muestra suficientemente clara de cómo el entorno creado, el natural y los avatares biológicos de nuestra especie han establecido una relación simbiótica cada vez más estrecha a raíz de los evidentes cambios en el hábitat.

¿Y esto qué quiere decir? Que el fortalecimiento de la relación establecida entre el entorno natural y/o creado y la vida humana, considerada esta última como la vida inteligente sobre el planeta, determina significativamente la permanencia sostenida de nuestra especie. Al respecto, la Teoría y práctica de la salud pública de Héctor Abad Gómez (1987; citado por Abad Faciolince, 2009), dice:

"La alternativa va siendo cada vez más clara: o nos comportamos como animales inteligentes $y$ racionales, respetando la naturaleza y acelerando en lo posible nuestro incipiente proceso de humanización, o la calidad de la vida humana se deteriora [...] si no nos comportamos racionalmente, sufriremos la misma suerte de algunas culturas y algunas estúpidas especies animales, de cuyo proceso de extinción $y$ sufrimiento nos quedan apenas restos fósiles. Las especies que no cambian biológica, ecológica o socialmente cuando cambia su hábitat, están llamadas a perecer después de un período de inenarrables sufrimientos".

Puede afirmarse que el transhumanismo ha acompañado de manera cada vez más abierta las discusiones de las diferentes comunidades a lo largo del tiempo, pero no ha sido comprendido en su totalidad por la mayor parte de la población. La visibilización del concepto, sus implicaciones en la dinámica individual y comunitaria, la construcción de acuerdos y planes de acción para la transformación cultural de cara a la humanización que plantea Abad Gómez (1987; citado por Abad Faciolince, 2019), el estudio y diseño de iniciativas para las fracciones de la comunidad que asuman dicha transformación, y su posterior puesta en marcha, son elementos indiscutibles para poder hacer del transhumanismo algo cotidiano, no solamente en las rutinas globales, 
sino también en la conciencia de la comunidad latinoamericana.

[1] Se confiere a la humanidad dos dimensiones, un alma (la cual contiene al pensamiento dentro de sus características) y un cuerpo (en contacto con el mundo material). Aunque puede decirse que esta postura aplica para todos los seres vivos, en este documento nos centraremos en el ser humano.

\section{Referencias}

Abad Faciolince, Héctor. (2009). El olvido que seremos. Editorial Planeta Colombiana.

Bradbury, R. (2019). Fahrenheit 451. Editorial Penguin Random House.

Gayozzo, P. (2021). Singularidad tecnológica y transhumanismo. Teknokultura. Revista de Cultura Digital y Movimientos Sociales, 18(2), 195-200. http://dx.doi.org/10.5209/TEKN.74056

Gómez Quintero, L. M. (2019) Educación STEM/STEAM como pretexto para la innovación en comunidades de aprendizaje. En N. M. Cáceres (Ed.), Educación STEM / STEAM, apuestas hacia la formación, impacto y proyección de seres críticos (pág. 56). Fondo Editorial Universitario Servando Garcés de la Universidad Politécnica Territorial de Falcón.
[2] Eso explica el castigo excesivo a la satisfacción sin tregua de los placeres corpóreos, que ha caracterizado a varias comunidades (particularmente religiosas) a lo largo del tiempo.
Gómez, M. (2021). Cultura para la transformación vs. la mentalidad de superviviente. Futuro Hoy, 2(1), 13-

15.https://doi.org/10.52749/fh.v2i1.4

Harari, Y. N. (2015) Homo Deus. Penguin Random House Grupo Editorial.

Oppenheimer, A. (2014) iCrear o morir! La esperanza de América Latina y las cinco claves de la innovación. Penguin Random House Grupo Editorial.

Serafini, L. (1985) Codex Seraphinianus.https://cutt.ly/Qn7UtKi

Sorgner, S. L. (2009). Nietzsche, the Overhuman, and

Transhumanism. Journal of Evolution and Technology 20(1). pp. 29-42. http://jetpress.org/v20/sorgner.pdf

\section{Cómo citar este artículo:}

Gómez, M. (2021). Comunidades Humanistas ante el Transhumanismo. Futuro Hoy, 2(2), 38-40. https://doi.org/10.52749/fh.v2i2.7

Esta obra está bajo licencia internacional Creative Commons 4.0 Reconocimiento 4.0. 